\title{
Palatability of Bufo marinus Tadpoles to a Predatory Fish Decreases with Development
}

\author{
Karen L. Lawler and Jean-Marc Hero \\ Department of Zoology, James Cook University of North Queensland, Townsville, Qld 4811, Australia. \\ A Cooperative Research Centre for Tropical Rainforest Ecology and Management. \\ ${ }^{\mathrm{B}}$ Present address: School of Applied Science, Griffith University Gold Coast, PMB 50 Gold Coast MC, Qld 4217, Australia.
}

Abstract

This investigation showed an ontogenetic shift in the palatability of Bufo marinus tadpoles by measuring consumption of tadpoles at three different developmental stages (newly hatched, intermediate and pre-metamorphic) by an Australian predatory fish, Lates calcarifer (barramundi). A known-palatable tadpole, Limnodynastes ornatus, was used as the control. B. marinus tadpoles at all developmental stages were unpalatable relative to a palatable alternative, with the later stages being the least palatable. Choice experiments further demonstrated that L. calcarifer were able to recognise and choose L. ornatus tadpoles in preference to those of B. marinus. Our experiments demonstrate that at all stages of development, B. marinus tadpoles were unpalatable to L. calcarifer. Contrary to the model proposed by Brodie and Formanowicz (1987), our results suggest an ontogenetic shift in palatability of B. marinus tadpoles to a vertebrate fish predator, with the later stages being less palatable.

\section{Introduction}

Since the introduction of Bufo marinus (the cane toad) to Queensland in 1935, it has, and is continuing to, spread rapidly throughout Australia (Straughan 1966). Its range now extends well into the Northern Territory and New South Wales and anecdotal reports suggest that this range extension has brought with it population declines of predators of anurans (Tyler 1989). The cane toad is now an integral component of the Australian fauna, and understanding the interactions between tadpoles of $\mathrm{B}$. marinus and native fish will contribute to our knowledge of how Australian predators respond to this introduced species.

In north Queensland, cane toads are often found in and adjacent to streams with many fish species, including barramundi (Lates calcarifer). L. calcarifer spend most of their life cycle in fresh water and reproduce in the brackish waters of river estuaries (Allen 1989). Presumably, L. calcarifer have been exposed to larvae of B. marinus in the Townsville region since the toad's introduction.

Tadpoles of Bufo species are unpalatable to many vertebrate predators (Voris and Bacon 1966; Wassersug 1971; Kruse and Stone 1984; Kats et al. 1988; Lawler 1989; Henrikson 1990; Denton and Beebee 1991). Wassersug (1971) reported that B. marinus tadpoles at developmental stages 30-32 (Gosner 1960) were distasteful to humans. The success of B. marinus in Australia may be due to the possession of an effective anti-predator defence used by the eggs, tadpoles and adults.

Heyer et al. (1975) suggested that there may be an ontogenetic shift in palatability as large B. marinus tadpoles tasted worse (to W. R. Heyer) than smaller tadpoles. In contrast, Brodie and Formanowicz (1987) proposed that newly hatched and pre-metamorphic stages of Bufo americanus were unpalatable to vertebrates while the intermediate developmental stages were palatable. However, they used results from experiments with an insect predator (odonate naiads) that pierces the skin and sucks body fluids. These invertebrate predators are less affected by tadpole chemical defences than are vertebrate predators (Peterson and Blaustein 1992). Further, they did not test the palatability of intermediate-stage tadpoles to a vertebrate predator. The Brodie and Formanowicz (1987) model does not conform to the results of Peterson and Blaustein (1992), who found no evidence of an ontogenetic shift in palatability of the tadpoles of Bufo boreas when exposed to aquatic insects (Lethocerus bugs and Dytiscis beetles).

We chose a naïve vertebrate fish predator (L. calcarifer) that masticates or bites its prey (and hence is likely to be influenced by distasteful chemicals) to ask whether there are ontogenetic shifts in palatability of B. marinus tadpoles. We also asked whether naïve L. calcarifer could distinguish between the unpalatable B. marinus tadpoles and a more palatable species, Limnodynastes ornatus, which is of similar size, colour and behaviour.

\section{Methods \\ General}

To provide insight into the interactions between $\mathrm{B}$. marinus and its predators, we tested the palatability of different developmental stages of B. marinus tadpoles to an Australian predatory fish, Lates calcarifer. As prey palatability is useful only in a relative sense (Brodie and Formanowicz 1987; Henrikson 1990), palatability of B. marinus tadpoles was assessed by comparing it with that of Limnodynastes ornatus [a known-palatable tadpole (Buffett 1995)] by means of no-choice experiments (a single fish predator and a single tadpole species). L. ornatus has larval growth and development patterns similar to that of B. marinus (R. Alford, personal communication). Choice experiments were also conducted to determine the ability of the fish to recognise and choose one tadpole species over another. 


\section{Animals}

Vertebrate predators experienced with Bufo species can learn to avoid them (Kruse and Stone 1984; Brodie and Formanowicz 1987). In Australia, B. marinus tadpoles often coexist with fish in the wild (Hero, unpublished data). Predators may learn to avoid unpalatable prey. To control for a possible predator-learning effect on these experiments, we conducted our experiments with naïve fish (farmed fish) rather than wild-caught fish. Juvenile L. calcarifer were obtained from a commercial aquaculture farm at Innisfail, north Queensland, and transported in fresh water with added oxygen to Townsville. The fish had been reared in brackish-water ponds to simulate estuarine conditions and individuals had no prior experience with any tadpole species. Experiments were conducted in late January and early February 1995 at James Cook University, Townsville, Australia.

Fish were placed individually into aerated containers and starved until the following morning when the experiments began (approximately $18 \mathrm{~h}$ ). Fish were also starved $12 \mathrm{~h}$ prior to transport (to reduce water pollution during transport) and travel time was approximately $6 \mathrm{~h}$. Thus, fish were not fed for approximately $36 \mathrm{~h}$ prior to the experiment. All fish were large enough to subdue and consume the tadpoles used in these experiments (Table 1).

Tadpoles of B. marinus were collected from a natural creek system in Townsville. Early-stage L. ornatus tadpoles were reared in the laboratory from eggs collected in the field and intermediate- and late-stage tadpoles were collected from a pond at a Townsville residence one week prior to the experiment. Tadpoles were kept in the laboratory at approximately $22^{\circ} \mathrm{C}$, maintained in 9-L opaque buckets filled with water from a recirculating freshwater system. Tadpoles were fed on lettuce ad libitum.

\section{Palatability Experiments}

Tadpoles were sorted into developmental stages by means of a dissecting microscope one day prior to the experiment to ensure that those tadpoles affected by the sorting process could be replaced before commencing the experiment. Dip nets used to handle tadpoles were flushed with water before and after use with B. marinus.

Two measures of palatability were recorded: the percentage of tadpoles eaten by all the fish, and the number of fish that ate at least one tadpole. This allowed us to test the same hypothesis in two different ways. Tadpoles at three different stages (Gosner 1960) of development—newly hatched (Stage 25), intermediate (Stages 29-33) and pre-metamorphic (Stages 38-41) — were tested. Descriptive statistics of 10 individual tadpoles randomly chosen from experiments for each species and each tadpole developmental stage are provided in Table 1.

Table 1. Descriptive measurements of Lates calcarifer and each of the three developmental stages of Bufo marinus and Limnodynastes ornatus

\begin{tabular}{|c|c|c|c|c|c|c|c|c|}
\hline \multirow[t]{2}{*}{ Species } & \multirow{2}{*}{$\begin{array}{c}\text { Stage of } \\
\text { development }\end{array}$} & \multirow[t]{2}{*}{ Experiment } & \multicolumn{3}{|c|}{ Length (mm) } & \multicolumn{3}{|c|}{ Mass (mg) } \\
\hline & & & Mean & s.e. & Range & Mean & s.e. & Range \\
\hline B. marinus & 25 & 2 & 1002 & 026 & $9.00-1135$ & $-{ }^{\mathrm{A}}$ & - & - \\
\hline B. marinus & $29-33$ & $1 \mathrm{~A}$ & 1530 & 041 & 12 20-16 25 & 3963 & 454 & $224-542$ \\
\hline L. ornatus & 25 & $1 \mathrm{~A}, 2$ & 1199 & 057 & $925-1465$ & 2480 & 290 & $118-399$ \\
\hline L. ornatus & 29-33 & $1 \mathrm{~B}$ & 2110 & 078 & $1750-2550$ & 16816 & 822 & 129 9-2129 \\
\hline L. ornatus & $38-41$ & $1 \mathrm{~B}$ & 2612 & 109 & $1990-3160$ & 28590 & 2491 & $1938-4281$ \\
\hline L. calcarifer & - & $1 \mathrm{~A}, 2$ & 8459 & 169 & 76 10-92 50 & $-^{\mathrm{A}}$ & - & - \\
\hline L. calcarifer & - & 1B & 10161 & 391 & $7755-11950$ & $-{ }^{\mathrm{A}}$ & - & - \\
\hline
\end{tabular}

${ }^{\mathrm{A}}$ Data not collected.

\section{Experiment 1}

Tadpole palatability for B. marinus and L. ornatus were measured at each of three different stages of development by using an naïve fish predator, L. calcarifer. Palatability of B. marinus tadpoles was compared directly with that of L. ornatus tadpoles. Hence, the experimental design was replicated with both B. marinus and L. ornatus tadpoles. Ten replicates of each of three developmental stages were tested. Each replicate contained one predator and 10 tadpoles all at the same stage of development. Each predator was used only once in a single replicate at a single stage of the tadpoles' growth. All predators were starved for approximately $36 \mathrm{~h}$ prior to the experiment (see above) and the experiment was terminated after $48 \mathrm{~h}$. Measurements of tadpole palatability were recorded after $0 \mathrm{fl} 5,1,2,4,8,15 \mathrm{fl} 5,32$ and $48 \mathrm{~h}$ to determine the rate of consumption. Tadpoles that were dead but uneaten were replaced so that each fish had the opportunity to consume an equal number of live tadpoles. 
Experimental containers were cylindrical 10-L clear plastic buckets (33 cm diameter and $14 \mathrm{~cm}$ deep) filled to $10 \mathrm{~cm}$ (7fl5 L) with water from a recirculating freshwater system and were constantly aerated. Due to limitations on laboratory space and the number of containers available (30), these experiments occurred over a two-week period. Experimental combinations (i.e. species and the developmental stages) depended on which tadpoles were available at the start of the experiments. Water temperatures during all experiments ranged from 24 to $26^{\circ} \mathrm{C}$.

Experiment 1 was completed in two stages: Experiment 1A measured the palatability of Stage 29-33 and 38-41 B. marinus tadpoles and Stage 25 L. ornatus tadpoles; Experiment 1B measured the palatability of Stage 25 B. marinus tadpoles and Stage 29-33 and 38-41 L. ornatus tadpoles. At the completion of each experiment, five fish in treatments with B. marinus tadpoles were selected randomly and fed five, Gosner Stage 25 L. ornatus tadpoles.

\section{Experiment 2}

Choice experiments were run simultaneously with Experiment $1 \mathrm{~A}$ to test whether $\mathrm{L}$. calcarifer recognise and consume tadpoles of $\mathrm{L}$. ornatus over B. marinus. Each of three replicates comprised one fish predator and 10 individuals of each tadpole species at Stage 25 (Gosner 1960). Experiments were carried out in 11-L opaque plastic buckets (26 cm diameter and $27 \mathrm{fl} 5 \mathrm{~cm}$ deep) filled to $19 \mathrm{~cm}(8 \mathrm{~L})$ with water from the recirculating freshwater system and constantly aerated. Water temperatures during all experiments ranged from 24 to $26^{\circ} \mathrm{C}$.

\section{Analysis of Data}

Data for B. marinus and L. ornatus were analysed separately as B. marinus tadpoles were clearly far less palatable and we were interested primarily in ontogenetic shifts in palatability within species. Differences in the consumption rates between tadpole developmental stages were determined, omitting fish that died during

the experiment (two in B. marinus experiments and one in a L. ornatus experiment). As the data were strongly non-normally distributed, non-parametric tests were used. The palatability of B. marinus Stage 25 and Stage 29-33 tadpoles were compared by means of a two-sample Mann-Whitney test (Stage 38-41 tadpoles were not included in the analysis as none was eaten in any replicate, and there was no variation in the number consumed). We did not use Kruskal-Wallis ANOVA to compare the three treatments because of the absence of variation in that treatment. Similarly, the palatabilities of L. ornatus Stage 29-33 and Stage 38-41 tadpoles were compared by means of a two-sample Mann-Whitney test (Stage 25 tadpoles were omitted as all tadpoles were eaten in all replicates). A two-tailed Fisher's exact test was used to examine the numbers of fish that had and had not eaten tadpoles at the end of each experiment.

\section{Results}

Experiment 1

Bufo marinus tadpoles at all stages of development tested were less palatable than were Limnodynastes ornatus tadpoles to Lates calcarifer (Fig. 1). Palatability of B. marinus tadpoles decreased with development (Fig. 1). Early-stage tadpoles were not significantly more palatable than Stage 29-33 tadpoles (Mann-Whitney, $\mathrm{P}=0 \mathrm{fl} 230, \mathrm{n}=18$ ) while Stage 38-41 B. marinus tadpoles were wholly unpalatable (Fig. 1). The number of fish that had eaten by the end of the experiment (Fig. 2) declined with increasing developmental stage of B. marinus tadpoles (Fisher's exact test, $\mathrm{P}=$ 0fl003). Five randomly chosen fish from the B. marinus treatments ate all of the L. ornatus tadpoles offered to them within $1 \mathrm{~h}$ of the termination of the experiment.

All stages of L. ornatus were highly palatable. There were no significant differences in palatability between Stages 29-33 and 38-41 in L. ornatus (Mann-Whitney, $\mathrm{P}=0 \mathrm{fl} 764, \mathrm{n}=19$ ) and all Stage 25 tadpoles were eaten (Fig. 1). This was also demonstrated by the numbers of fish that ate within each developmental stage (Fig. 2) (Fisher's exact test, $\mathrm{P}=0 \mathrm{fl} 195$ ).

During the experiments, tadpoles of B. marinus were found dead and uneaten (23 tadpoles were replaced from 10 of the $30 \mathrm{~B}$. marinus treatments) while remaining tadpoles of L. ornatus were nearly always alive (1 dead tadpole replaced in 30 treatments). We observed mouthing and rejection of $\mathrm{B}$. marinus tadpoles on several occasions throughout the experiments. 


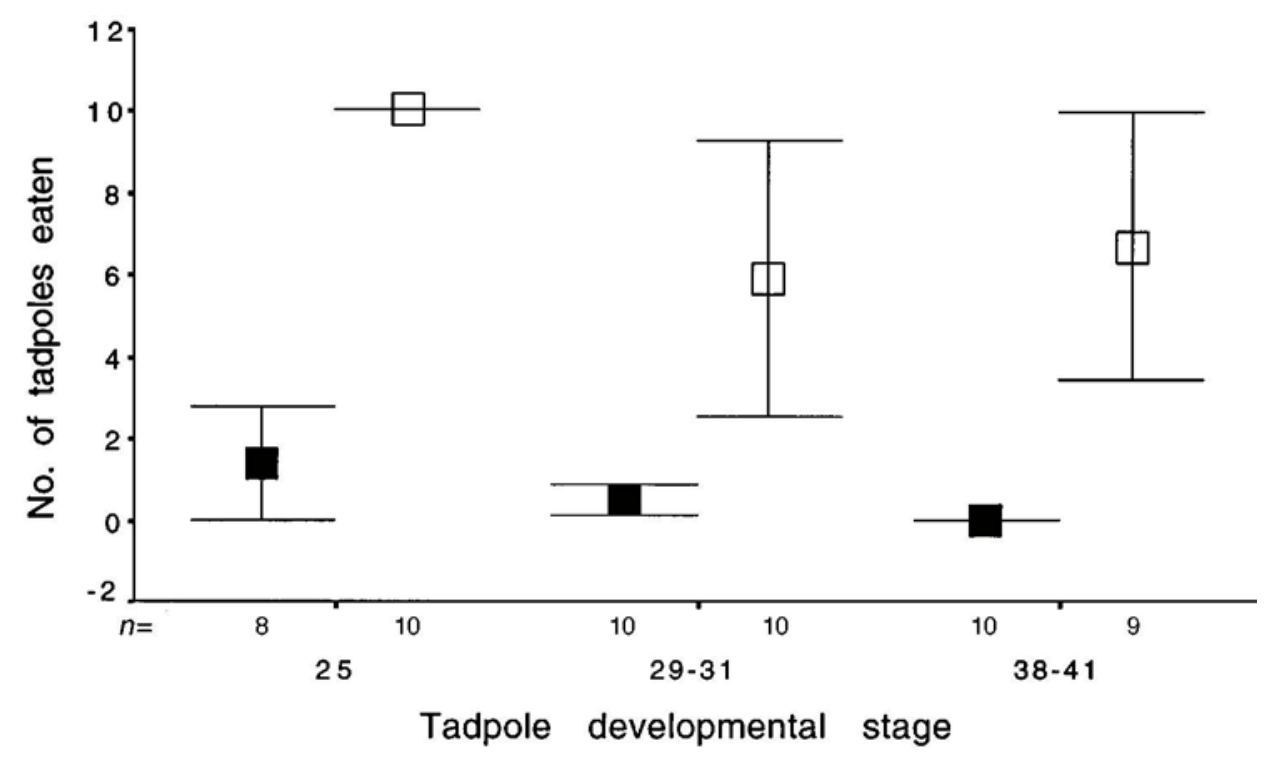

Fig. 1. Ontogenetic shifts in the mean number of tadpoles of Bufo marinus (") and Limnodynastes ornatus ( ${ }^{\square}$ ) eaten by fish (Lates calcarifer) in palatability experiments after $48 \mathrm{~h}$. Error bars represent 95\% confidence intervals.

\section{Experiment 2}

Lates calcarifer preferred L. ornatus tadpoles over B. marinus tadpoles (Fig. 3). The data also show that B. marinus tadpoles were eaten only after $15 f 15 \mathrm{~h}$, when most of the palatable

L. ornatus had been consumed (Fig. 3).

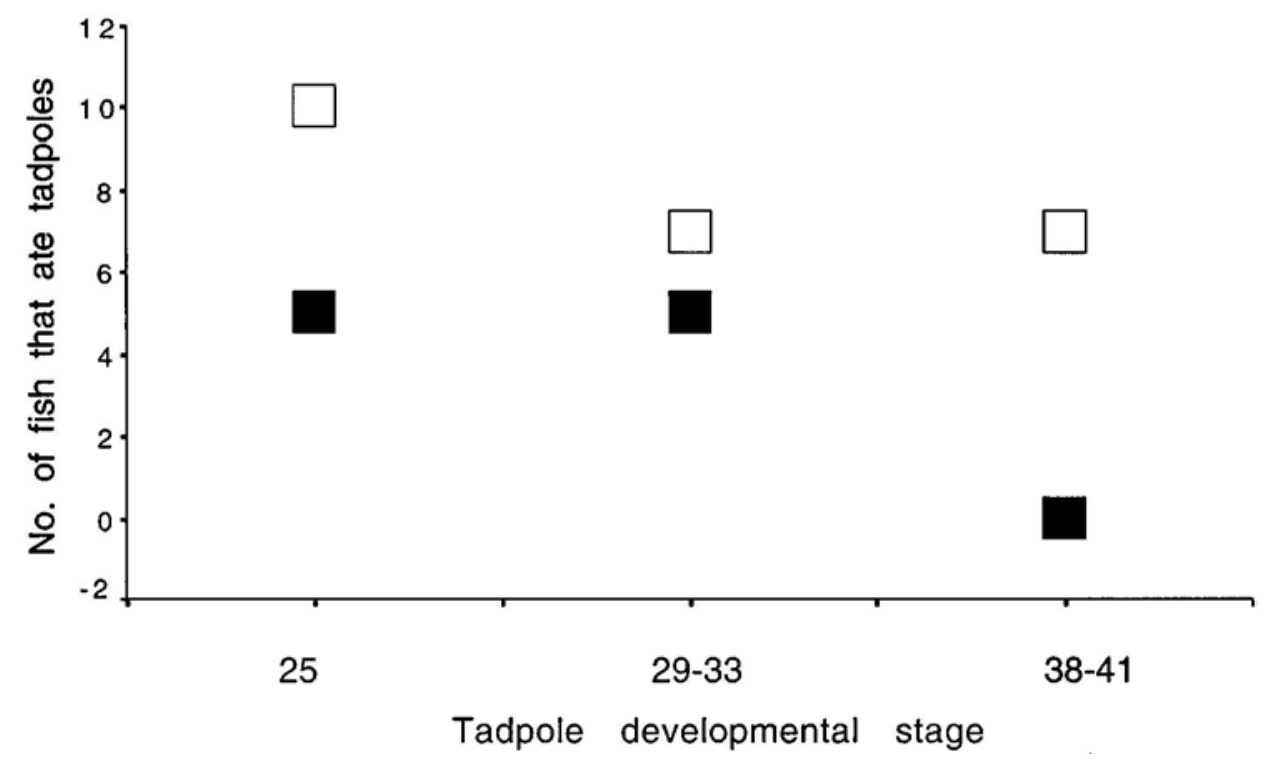

Fig. 2. The number of fish (Lates calcarifer) that had eaten tadpoles of Bufo marinus (") and Limnodynastes ornatus ( $\left.{ }^{\square}\right)$ in palatability experiments after $48 \mathrm{~h}$. 


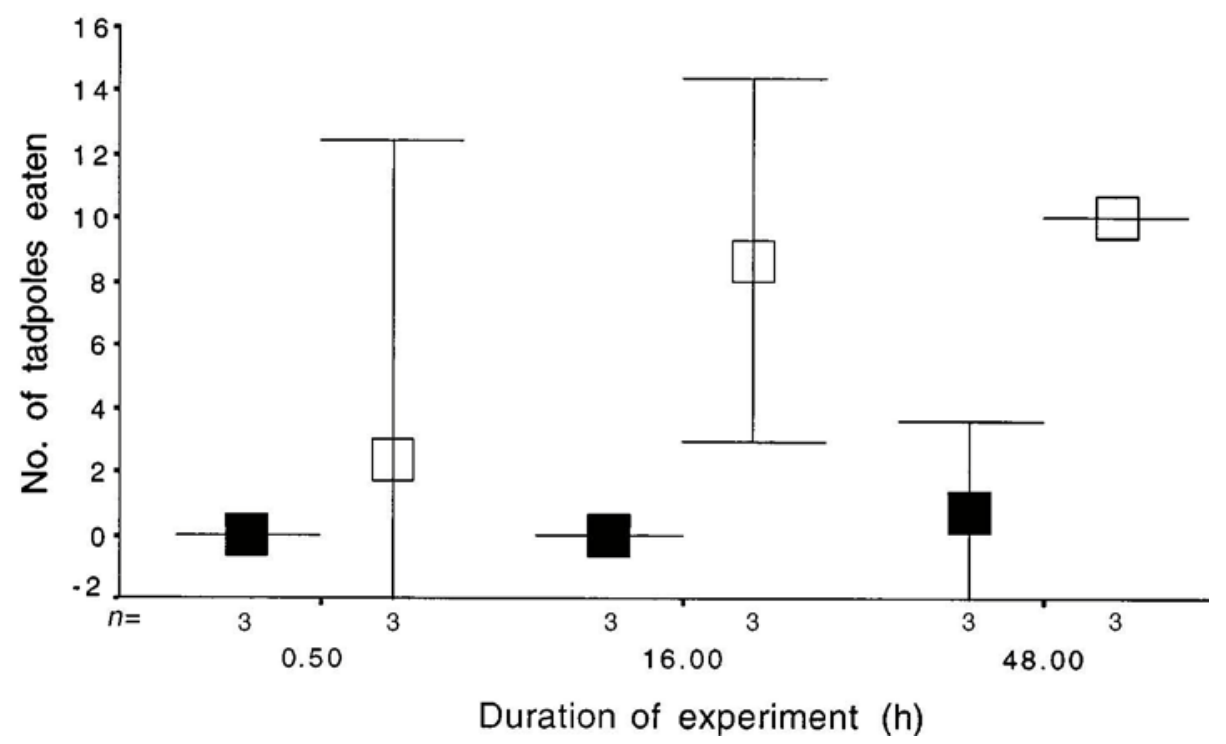

Fig. 3. The mean number of tadpoles of Bufo marinus (") and Limnodynastes ornatus ( ${ }^{\square}$ ) eaten by fish (Lates calcarifer) in choice experiments measured at three periods over $48 \mathrm{~h}$. Error bars represent 95\% confidence intervals.

\section{Discussion}

These experiments clearly showed that B. marinus tadpoles at all stages of development tested were unpalatable to naïve barramundi fish (L. calcarifer). The results are consistent with those of similar studies with other vertebrate predators (Wassersug 1971; Heyer et al. 1975; Kats et al. 1988). B. marinus tadpoles were consumed only after the fish had undergone a lengthy period without feeding. Furthermore, few B. marinus tadpoles were eaten when alternative prey were available. These results, and the fact that the fish readily ate L. ornatus tadpoles under the same conditions, strongly suggest that B. marinus tadpoles exude a repellent chemical, as has been suggested previously for this species (Wassersug 1971; Heyer et al. 1975) as well as for other Bufo species (Voris and Bacon 1966; Brodie et al. 1978; Kruse and Stone 1984) and other amphibian species (Walters 1975; Garton and Mushinsky 1979; Brodie and Formanowicz 1981). We think the differential results are due to a chemical repellent as the behaviour and morphology of L. ornatus and B. marinus are similar. The large number of dead but uneaten B. marinus tadpoles found in the experiments further supports the chemical-repellent hypothesis as it suggests that fish were mouthing the tadpoles but refusing to eat them.

Flier et al. (1980) demonstrated that bufodienolides are present in the skin of both B. marinus adults and pre-metamorphic tadpoles, and suggested that these are probably responsible for defence against predation. However, the granular glands, thought to be the main source of production of toxins in Bufo species (Formanowicz and Brodie 1982), have been reported to appear only during or after metamorphosis in tadpoles of Gastrophryne carolinensis (Garton and Mushinsky 1979), Rana sylvatica (Formanowicz and Brodie 1982) and B. marinus (Flier et al. 1980). Before the glands develop fully, the precursor cells may produce small amounts of toxins (Hews 1988) while larger amounts and/or concentrations are produced as the glands develop in later stages (Formanowicz and Brodie 1982). Our results suggest an ontogenetic shift in palatability of B. marinus tadpoles to a vertebrate fish predator, with the later stages being less palatable.

Development of toxin-producing glands would explain the ontogenetic increase in unpalatability of $\mathrm{B}$. marinus tadpoles observed in this study. Alternatively, increasing unpalatability of the later stages may simply be a function of their larger size (increased surface area), and hence the larger dose of repellent encountered by predators (Heyer et al. 1975). Brodie et al. (1978) noted the same trend in increasing unpalatability of tadpoles of different stages controlling for size, which suggests that size is less important than the development of chemical-producing glands. Our results do not agree with the model proposed by Brodie and Formanowicz (fig. 1, 1987), which predicts that intermediate stages of Bufo tadpoles are palatable to vertebrate predators while the newly hatched and the pre-metamorphic stages are unpalatable.

For invertebrate predators, the ontogenetic shift outlined in the Brodie and Formanowicz (1987) model (and observed in their naiad predation experiments) may be explained by ontogenetic changes in tadpole mobility alone, and may not be related to toxicity. Tadpoles at intermediate stages may be more mobile (Brodie and Formanowicz 1987) and hence more vulnerable to odonate naiad predators (Azevedo-Ramos et al. 1992; Chovanec 1992). In similar experiments, Peterson and Blaustein (1992) found no evidence of an ontogenetic shift in palatability of Bufo boreas to several invertebrate predators (giant water bugs and diving beetles). Further experiments, investigating ontogenetic shifts in palatability and behaviour of B. marinus tadpoles to invertebrate predators, would facilitate the separation of these confounding attributes.

Predatory fishes have demonstrated their ability to distinguish between more and less palatable tadpoles (Kruse and Stone 1984). In this study, L. calcarifer were able to recognise B. marinus tadpoles, and in a choice situation always chose to consume the more palatable 
species even though the fish were naïve. Hence, in nature, B. marinus tadpoles are unlikely to be eaten by predatory fish, first, because they are unpalatable and, second, as there are often alternative prey available to them. Furthermore, in the more complex natural environment, B. marinus tadpoles exhibit other means of escaping predation, for example, schooling (Beiswenger 1975; Henrikson 1990; Waldman 1982; Wassersug 1971). Limnodynastes ornatus breed in ephemeral waterbodies and consequently their more palatable tadpoles do not usually coexist with fish in the wild (Hero, unpublished data). The less palatable B. marinus tadpoles are occupants of both permanent and non-permanent pools, often with fish present (Hero, unpublished data). Hence, our palatability experiments lend support to the hypothesis that tadpole species coexisting with fish are more likely to have chemical anti-predator defences than species that do not coexist with fish (Kruse and Francis 1977; Kats et al. 1988; Henrikson 1990).

The present results demonstrate that B. marinus tadpoles are unpalatable to L. calcarifer, suggesting that significant numbers of B. marinus tadpoles are unlikely to be eaten by Australian fish predators. An interesting avenue for further research would be to repeat these experiments, with wild-caught L. calcarifer that coexist with B. marinus, to examine behavioural differences in how fish respond to unpalatable tadpoles.

\section{Acknowledgments}

We thank I. Lawler for his help collecting and sorting tadpoles; I. Lawler and R. Alford for statistical assistance; and M. Crossland for donating L. ornatus tadpoles. M. Crossland,

I. Lawler, E. Lawler, R. Alford, Edmund Brodie Jr and anonymous reviewers gave valuable comments on this manuscript.

\section{References}

Allen, G. R. (1989). 'Freshwater Fishes of Australia.' (TFH Publications: New Jersey.)

Azevedo-Ramos, C. B. A., Van Sluys, M., Hero, J.-M., and Magnusson, W. E. (1992). Influence of tadpole velocity on predation by odonate naiads. Journal of Herpetology 26, 335-337.

Beiswenger, R. E. (1975). Structure and function in aggregations of tadpoles of the American toad, Bufo marinus. Herpetologica 31, $222-233$.

Brodie, E. D., Jr, and Formanowicz, D. R. Jr (1981). Larvae of the predacious diving beetle Dytiscus verticalis acquire an avoidance response to skin secretions of the newt Notophthalmus viridescens. Herpetologica 37, 172-176.

Brodie, E. D., Jr, and Formanowicz, D. R., Jr (1987). Antipredator mechanisms of larval anurans: protection of palatable individuals. Herpetologica 43, 369-373.

Brodie, E. D., Jr, Formanowicz, D. R., Jr, and Brodie, E. D. III. (1978). The development of noxiousness of Bufo americanus tadpoles to aquatic insect predators. Herpetologica 34, 302-306.

Buffett, Y. M. (1995). Prey survival strategies: the influence of palatability and behaviour. B.Sc. Hons Thesis, James Cook University of North Queensland, Townsville.

Chovanec, A. (1992). The influence of tadpole swimming behaviour on predation by dragonfly nymphs. Amphibia-Reptilia 13, 341-349.

Denton, J., and Beebee, T. J. C. (1991). Palatability of anuran eggs and embryos. Amphibia-Reptilia 12, 111-112.

Flier, J., Edwards, M. W., Daly, J. W., and Myers, C. W. (1980). Widespread occurrence in frogs and toads of skin compounds interacting with the ouabain site of $\mathrm{Na}^{+}, \mathrm{K}^{+}$-ATPase. Science 208, 503-505.

Formanowicz, D. R., Jr, and Brodie, E. D., Jr (1982). Relative palatabilities of members of a larval amphibian community. Copeia 1982, 91-97.

Garton, J. D., and Mushinsky, H. R. (1979). Integumentary toxicity and unpalatability as an antipredator mechanism in the narrow mouthed toad, Gastrophryne carolinensis. Canadian Journal of Zoology 57, 1965-1973.

Gosner, K. L. (1960). A simplified table for staging anuran embryos and larvae with notes on identification. Herpetologica 16, 183-190.

Henrikson, B. (1990). Predation on amphibian eggs and tadpoles by common predators in acidified lakes. Holarctic Ecology 13, 201-206.

Hews, D. K. (1988). Alarm response in larval western toads, Bufo boreas: release of larval chemicals by a natural predator and its effect on predator capture efficiency. Animal Behaviour 36, 125-133.

Heyer, R. W., McDiarmid, R. W., and Weigmann, D. L. (1975). Tadpoles, predation and pond habitats in the tropics. Biotropica 7, $100-111$.

Kats, L. B., Petranka, J. W., and Sih, A. (1988). Antipredator defences and the persistence of amphibian larvae with fishes. Ecology 69, $1865-1870$.

Kruse, K. C., and Francis, M. C. (1977). A predation deterrent in larvae of the bullfrog, Rana catesbeiana. Transactions of the American Fish Society 106, $248-252$.

Kruse, K. C., and Stone, B. M. (1984). Largemouth bass (Micropterus salmonoides) learn to avoid feeding on toad (Bufo) tadpoles. Animal Behaviour 32, 1035-1039.

Lawler, S. P. (1989). Behavioural responses to predators and predation risk in four species of larval anurans. Animal Behaviour 38, $1039-1047$.

Peterson, J. A., and Blaustein, A. R. (1992). Relative palatabilities of anuran larvae to natural aquatic insect predators. Copeia 1992, 577-584.

Straughan, I. R. (1966). The natural history of the 'cane toad' in Queensland. Australian Natural History 15, $230-232$.

Tyler, M. (1989). ‘Australian Frogs.’ (Viking O’Neil: Melbourne.)

Waldman, B. (1982). Sibling association among schooling toad tadpoles: field evidence and implications. Animal Behaviour 30, 700-713.

Walters, B. (1975). Studies of interspecific predation within an amphibian community. Journal of Herpetology 9, $267-279$.

Wassersug, R. (1971). On the comparative palatability of some dry-season tadpoles from Costa Rica. American Midland Naturalist 86, $101-109$.

Voris, H. K., and Bacon, J. P., Jr (1966). Differential predation on tadpoles. Copeia 1966, 594-598. 